\title{
Carbetocin and Oxytocin in the Active Management of Third Stage of Labor after Vaginal Birth of Baby
}

\author{
*Barua $H R^{1}$, Barua RR ${ }^{2}$, Barua $S^{3}$, Barua AK ${ }^{4}$, Begum $K^{5}$
}

\begin{abstract}
Postpartum hemorrhage (PPH) is one of the major contributors to maternal mortality and morbidity worldwide. Active management of the third stage of labor has been proven to be effective in the prevention of PPH. Carbetocin; a long-acting Oxytocin agonist appears to be a promising agent for the prevention of $\mathrm{PPH}$. In this study Carbetocin is used for the active management of third stage of labor to prevent PPH. Two hundred pregnant women from July 2015 to December 2015 at Rangamati Medical College Hospital, Rangamati, Bangladesh were included in this study. The patients were divided into two groups: Group- 1 (100 women) were received $100 \mu \mathrm{g}$ Carbetocin intravenously and group- 2 (100 women) received $10 \mathrm{IU}$ Oxytocin intramuscularly and both doses were single. These uterotonics were injected at anterior shoulder after the delivery of the baby. Significant difference was observed between the Carbetocin and Oxytocin receiving groups regarding amount of blood loss $(335.70 \pm 117.71$ versus $375.12 \pm$ 145.30), PPH (3 \% versus 12\%), need of use of other uterotonics (18\% versus 30\%) and the difference in hemoglobin percent before and after delivery $(0.58 \pm 0.34$ versus $0.97 \pm$ 0.52). All these parameters were lower in Carbetocin group except hemoglobin level which is higher in group- 2 during 24 hours after delivery. Moreover, blood transfusion was not indicated in group-1. In conclusion, Carbetocin is superior to Oxytocin in prevention of post partum hemorrhage at the third
\end{abstract}

1. *Dr. Hena Rani Barua, Senior Consultant, Obstetric and Gynecology, Rangamati Medical College Hospital, Rangamati, Bangladesh. Email: baruarita @yahoo.com

2. Dr. Rita Rani Barua, Associate Professor, Pathology, Dr. Sirajul Islam Medical College, Dhaka, Bangladesh.

3. Dr. Sushanta Barua, Indoor Medical Officer, Neuromedicine, Dhaka Medical College, Dhaka, Bangladesh.

4. Dr. Ajoy Kishore Barua, Medical Officer, Bandarban Sadar Hospital, Bandarban Hill District, Bangladesh.

5. Dr. Kohinoor Begum, Professor, Obstetric and Gynecology, Popular Medical College, Dhaka, Bangladesh.

* Corresponding Author. stage of vaginal delivery with minimal homodynamic changes and side effects.

Key words: Carbetocin, Oxytocin, Active management of third stage of labor, Postpartum Hemorrhage.

\section{INTRODUCTION:}

Post-partum hemorrhage $(\mathrm{PPH})$ is the leading cause of maternal death worldwide; with an estimated mortality rate of $1,40,000$ per year or one maternal death in every 4 minutes ${ }^{1}$. $\mathrm{PPH}$ occurs in $5 \%$ of all deliveries and is responsible for $28 \%$ of maternal mortality in Bangladesh ${ }^{2}{ }^{3}$. The majority of these deaths occur within 4 hours of delivery which indicates that these are a consequence of the third stage of labour4-5. Fatal PPH results in several morbidities like severe iron deficiency anemia, Sheehan's syndrome, coagulopathy, poor lactation and organ damage with associated hypotension, shock and risk of hysterectomy6.

$\mathrm{PPH}$ is defined as blood loss more than $500 \mathrm{ml}$ after vaginal delivery and more than $1000 \mathrm{ml}$ after caesarean section that occurs within the first 24 hours 7 . Blood loss $500-1000 \mathrm{ml}$ is called minor $\mathrm{PPH}$ and $>1000 \mathrm{ml}$ is major PPH. Many patients known to be high risk for developing PPH such as two or more caesarean sections, multiple pregnancy, placenta praevia, abruptio placenta, fetal macrosomia, history of $\mathrm{PPH}$, anemia, age > 40 years , uterine myoma, polyhydromnios 8 .

Uterine atony is the major cause of hemorrhage at the third stage of labour and at the early postpartum period. Therefore; active management is more effective than expectant management of the third stage of labor. Third stage of labor is that period following the delivery of baby till placental delivery9-10.

$\mathrm{PPH}$ can be prevented by administration of uterotonic drugs. Intramuscular Oxytocin (10 IU) usually prevent PPH in low risk vaginal and caesarean delivery or intravenous infusion (20-40 IU in $1000 \mathrm{ml} \mathrm{5 \%} \mathrm{Dextrose,} 150 \mathrm{ml} / \mathrm{h}$ ) having $3-5$ minutes half life 11-12. Carbetocin is an alternate long acting synthetic uterotonic with a half life of 40 minutes and uterine contractions occur in less than 2 minutes after intravenous administration of optimal dosage of $100 \mu \mathrm{g}$ 13. Carbetocin is more effective to control maternal mortality rate preventing $\mathrm{PPH}$. However, a little is known about the effect and advantage of the use of Carbetocin in the management of third stage of vaginal delivery. Therefore, a case- control study using carbetocin and oxytocin was conducted at Rangamati Medical College Hospital to prevent PPH. 


\section{METHODS:}

This study was conducted on 200 pregnant women attending the Obstetrics and Gynecology department, Rangamati Medical College Hospital from July 2015 to December 2015. The work was approved by local ethical committee and informed consent was taken from the patients regarding its importance, expected value and outcome. All participants were 37 - 40 weeks of gestation with at least two risk factors for developing atonic PPH. Risk factors included were primi gravida $>36$ years, history of prolonged labor $>12$ hours, multiple pregnancy, PPH, BMI $>35$ and estimated fetal weight more than $4 \mathrm{~kg}$. Participants with pre-eclampsia, placenta praevia, cardiac, renal, liver diseases, bleeding disorders, epilepsy and known hypersensitivity to carbetocin or oxytocin were excluded from the study group.

All the patients were subjected to full history taking, general, per abdominal and obstetric examination. Ultrasound scan, complete blood count, liver function test and coagulation profile were also done. Firstly we recruited one hundred women of group 1 who received a single dose of $100 \mu \mathrm{g} I / \mathrm{V}$ carbetocin (case group I) followed by another one hundred women of group 2 who received a single dose of $10 \mathrm{IU}$ I/M oxytocin. Both drugs were administered following delivery of the anterior shoulder of the baby in singleton pregnancy and delivery of the anterior shoulder of second twin in multiple pregnancies.

All the participants were follow- up upto 24 hrs. The uterine tone and amount of blood loss were noted and the need for further uterotonics was checked for two minutes after giving the drugs. Blood loss was estimated by usual method of by counting the number of pads. Blood loss $500-1000 \mathrm{ml}$ was considered as minor PPH and blood loss $>1000 \mathrm{ml}$ was considered as major PPH. Hemoglobin level was assessed 24 hrs after delivery.

Systolic and diastolic blood pressure was measured immediately after delivery and 30 and 60 minutes after delivery of the baby. Possible side effects like nausea, vomiting, flushing, tachycardia, shivering, dizziness, headache, palpitation, dyspnea and itching were recorded.

Data was statistically analyzed and described in terms of mean \pm standard deviation $( \pm S D), \quad$ frequencies and in percentage when appropriate. Comparison of numerical variables between the study groups was done using independent t-test. For comparing categorical data, Chi-square $\left(X^{2}\right)$ test was performed. P-values less than 0.05 were considered statistically significant. All statistical calculations were done using complete program SPSS.

\section{RESULTS:}

Table- I. Distribution of population by the characteristics of the patients

\begin{tabular}{lcc}
\hline & $\begin{array}{c}\text { Carbetocin } \\
(\mathrm{n}=100)\end{array}$ & $\begin{array}{c}\text { Oxytocin P-value } \\
(\mathrm{n}=100)\end{array}$ \\
\hline Age (years) & $30.80 \pm 6.52$ & $30.78 \pm 6.42$ \\
BMI $\left(\mathrm{kg} / \mathrm{m}^{2}\right)$ & $27.62 \pm 4.52$ & $26.20 \pm 4.52$ \\
Gestational age (weeks) & $39.42 \pm 1.25$ & $39.30 \pm 1.35$ \\
Gravidity & $2.48 \pm 1.11$ & $2.35 \pm 1.04$ \\
Parity & $2.56 \pm 1.15$ & $2.48 \pm 1.25$ \\
Duration of 1st stage of labor (hrs) & $12.40 \pm 3.60$ & $12.45 \pm 3.45 \mathrm{NS}$ \\
Duration 2nd stage of labor (min) & $81.78 \pm 20.25$ & $82.65 \pm 18.62$ \\
Duration of 3rd stage of labor (min) & $4.55 \pm 2.25$ & $4.53 \pm 2.08$ \\
\hline (min) & & \\
\hline
\end{tabular}

* Data are presented as mean \pm SD. NS; Not significant

Two hundred pregnant women were classified into two groups: group 1 included one hundred patients who received carbetocin and group 2 included another one hundred patients who received oxytocin. Baseline characteristics of the patients were summarized in Table 1. There was no significant difference between the groups in age, body mass index, gravity, parity and gestational age. Disparity was not observed between the groups regarding the duration of 1st, 2nd and 3rd stages of labor (Table- I).

Table- II. Distribution of population by the amount of bleeding and usage of other uterotonics

\begin{tabular}{lccc}
\hline & $\begin{array}{c}\text { Carbetocin } \\
(\mathrm{n}=100)\end{array}$ & $\begin{array}{c}\text { Oxytocin } \\
(\mathrm{n}=100)\end{array}$ & P-value \\
\hline Amount of bleeding $(\mathrm{ml})$ & $335.70 \pm 117.71$ & $375.12 \pm 145.30$ & \\
PPH $(>500-<1000 \mathrm{ml})$ & $3 \%$ & $12 \%$ & \\
PPH $(>1000 \mathrm{ml})$ & 0 & $1 \%$ & 0.032 \\
Use of other uterotonics & $18 \%$ & $30 \%$ & \\
Needs for blood transfusion & 0 & 2 & \\
\hline${ }^{*}$ Data are presented as mean \pm SD. ${ }^{*}$ Data are presented as number and percent.
\end{tabular}

Blood loss, PPH, use of other uterotonics, hemoglobin levels before and $24 \mathrm{hrs}$ after delivery were significantly lower in the carbetocin group (Group 1) than oxytocin group (Group 2). There was significant difference between the two groups regarding occurrence of major $\mathrm{PPH}$ and the need for blood transfusion (Table II). 
Table III. Distribution of population by side effects of drugs

\begin{tabular}{lcc}
\hline Side effects of drugs & Carbetocin $(\mathbf{n}=\mathbf{1 0 0})$ & Oxytocin $(\mathbf{n}=\mathbf{1 0 0})$ \\
\hline Dizziness & $1(1 \%)$ & 0 \\
Shivering & 0 & $1(1 \%)$ \\
Flushing & $1(1 \%)$ & $2(2 \%)$ \\
Nausea & $3(3 \%)$ & $2(2 \%)$ \\
Vomiting & $4(4 \%)$ & $2(2 \%)$ \\
Tachycardia $(>100 \mathrm{~b} / \mathrm{min})$ & $8(8 \%)$ & $2(2 \%)$ \\
Palpitation & $2(2 \%)$ & $3(3 \%)$ \\
Dyspnea & $2(2 \%)$ & $3(3 \%)$ \\
No side effects & $79(79 \%)$ & $85(85 \%)$ \\
* Data are presented as number and percent. &
\end{tabular}

On carbetocin group there was no major PPH and no need of blood transfusion. Nausea, vomiting, palpitation, shivering, flushing, dizziness, headache, dyspnea and itching were found in both groups except tachycardia which was more in group 2 (Table III)

\section{DISCUSSION:}

The result of this study has shown that carbetocin is superior to oxytocin for the prevention of post partum hemorrhage by active management of third stage of labor. This fact can be explained by the known longer half-life of carbetocin compared to oxytocin resulting in a more uterine response in terms of frequency and amplitude of uterine contractions.

In this study, it is found that the amount of blood loss after delivery is significantly lower in women who received carbetocin than those who received oxytocin. We also found that need for additional uterotonics and blood transfusion were lower among carbetocin group. Hemoglobin level before and after delivery was also less in carbetocin group.

Boucher et al.14 have randomized 160 women undergoing vaginal delivery with at least one risk factor for $\mathrm{PPH}$ to receive either carbetocin $100 \mu \mathrm{g} / \mathrm{M}$ or oxytocin $10 \mathrm{IU}$ I/V infusion over two hours. The need for uterine massage and other uterotonics were significantly lower in the carbetocin group, these results are in agreement with our study. But they find no significant difference in the amount of blood loss or the difference in hemoglobin level before and after delivery between the groups. The difference between these results and our study can be explained by the difference in the route and dose of oxytocin.

Attilakos et al;15 has randomized 377 caesarean section patients received either IV carbetocin $100 \mu \mathrm{g}$ or IV oxytocin 5 IU after the delivery of the baby. The carbetocin group needed significantly less additional uterotonics which concordant with our findings. However; they found no significant difference regarding blood loss or hemoglobin level before and after operation between the two groups.
This disagrees with our results and may be in the difference in the studied population. We studied women with risk factors for atonic PPH undergoing vaginal delivery, but Attilakos et al. studied on caesarean sections with or without risk factor for PPH. Leung et al ;16 compares the efficacy and safety of intramuscular carbetocin with IM syntometrine in preventing primary $\mathrm{PPH}$ in a prospective double-blinded, randomized controlled trail. They find IM carbetocin is as effective as IM syntometrine to prevent primary $\mathrm{PPH}$ following vaginal delivery. It is less likely to induce hypertension and other side effects. In this study there is no significant difference between the two groups regarding side effects except tachycardia. These results are also supported by other researchers 11, 15 .

In conclusion carbetocin is a better uterotonic than oxytocin to maintain adequate uterine tone with minimal homodynamic changes and side effects. Therefore, carbetocin should be routinely used in active management of third stage of labor during vaginal delivery to prevent post partum hemorrhage.

\section{REFERENCES:}

1. Abuzahr C, Global burden of maternal death and disability. Br Med Bult 2003; 67:1-11.

2. Reynders FC, Senten L. Tjalma W, Jacquemyn Y. Postpartum hemorrhage: Practical approach to a life threatening complication. Clin Exp Obstet 2006; 33:81-4.

3. Subtil D, Somme A, Ardiet E, Mossers D. Postpartum hemorrhage frequency, consequences in terms of health status and risk factor before delivery. J Gynecol Obstet Biol Reprod 2004; 33: 9-16.

4. Ramanathan G, Arulkumaran S, Postpartum hemorrhage. Curr Obstet Gynecol 2006; 16:6-13.

5. Kane TT, el- kaldy AA, Saleh S, Hage M, Stanback J, Potter L. Maternal mortility in Giza, Egypt: Magnitude, causes and prevention. Stud Fam Plann 1992; 23:45-57.

6. Larciprete G, Montaganoli C, Frigo M, Panetta V, Todde C, Zuppani B, et al. Carbetocin versus oxytocin in casearean section with high risk of postpartum hemorrhage. J Prenat Med 2013; 7:12-18.

7. World Health Organization. The world health report 2005: make every mother and child count, Geneva 2005.

8. Royal college of Obstetrician and Gynecologist. Prevention and management of postpartum hemorrhage, Green top guidelines no. 52 minor revisions November 2009 and April 2011.

9. Knight M, Callaghan WM, Berg C, Alexanders, Bourier-Colle MH, Ford JB. Trends in postpartum hemorrhage in high resource countries: a review and recommendations from the Int. postpartum hemorrhage 
collaborative group. BMC pregnancy child birth 2009; 9-55.

10. Su LL, Chong YS, Samuel M. Oxytocin agonists for preventing postpartum hemorrhage. Cochrane Database Syst Rev 2012; 15: CD005457.

11. Moertl MG, Friedrich S, Kraschl J. Wadsac KC, Lang U, Schlemboch D. Hemodynamic effects of carbetocin and oxytocin given as intravenous bolus on women undergoing caesarean delivery a randomized trial. BJOG 2011; 118:1349-56.

12. Engstrom T, Barth T, Melin P, Vilhardt H. Oxytocin receptor binding and uterotonic actuality of carbetocin and its metabolites following enzymatic degradation. Eur J Pharmacol 1998; 355:203-10.

13. Sweeney G. Holbrook AM, Levine M, Yip M, Alfredson K, Cappi S. Pharmacokinetics of carbetocin, along oxytocin analogue, in non-pregnant women. Curr Ther Res 1990; 47:528-40.

14. Boucher M, Nimrod CA, Tawagi GF, Meeker TA, Rennicks White RE, Varin J. Comparison of carbetocin and oxytocin for the prevention of postpartum hemorrhage following vaginal delivery: a double-blind randomized trail. J Obstet Gynaecol 2004; 26: 481-88.

15. Attilakos G, Psaroudakis D, Ash J, Bouchanan R, Winter C, Donald F, Hunt LP, Draycott T. Carbetocin versus oxytocin for the prevention of post partum hemorrhage following caesarean section; the result of a double-blind randomized trial. BJOG 2010; 117: 929-36.

16. Leung SW, NgPS, Wong WY, Cheung TH. A randomized trial of carbetocin versus syntometrene in the management of the third stage of labor. BJOG 2006; 113:1459-64. 